\title{
A conceptual space for episodic and semantic memory
}

\author{
David C. Rubin ${ }^{1,2}$ (I) \\ Accepted: 28 January 2021 / Published online: 1 March 2021 \\ (C) The Psychonomic Society, Inc. 2021
}

\begin{abstract}
I propose a model that places episodic, semantic, and other commonly studied forms of memory into the same conceptual space. The space is defined by three dimensions required for Tulving's episodic and semantic memory. An implicit-explicit dimension contrasts both episodic and semantic memory with common forms of implicit memory. A self-reference dimension contrasts episodes that occurred to one person with semantic knowledge. A scene dimension contrasts episodes that occurred in specific contexts with context-free semantic information. The three dimensions are evaluated against existing behavioral and neural evidence to evaluate both the model and the concepts underlying the study of human memory. Unlike a hierarchy, which has properties specific to each category, the dimensions have properties that extend throughout the conceptual space. Thus, the properties apply to all forms of existing and yet-to-be-discovered memory within the space. Empty locations in the proposed space are filled with existing phenomena that lack a clear place in current theories of memory, including reports of episodic-like memories for events reported to but not witnessed by a person, fictional narrative accounts, déjà vu, and implicit components contributing to personality, the self, and autobiographical memory.
\end{abstract}

Keywords Cognition $\cdot$ Consciousness $\cdot$ Episodic memory $\cdot$ Mental representation $\cdot$ Semantic memory

The call for papers for this special issue of Memory \& Cognition poses the following challenge: "The interactions between semantic and episodic memory are so entrenched and nuanced that it may no longer make sense to distinguish them and to favor instead a different understanding of the processes involved in the tasks that traditionally were considered either episodic or semantic." I offer a solution by making the key processes used to distinguish episodic from semantic memory into dimensions of a conceptual space. Episodic and semantic memory are placed into that space along with other types of memory that are not in the current classification.

Tulving's episodic-semantic dichotomous memory distinction defines a hierarchy with explicit memory as its highest node. If the node of implicit memory implied by explicit memory is included, it becomes the basis for Squire's (1987) hierarchy of memory, the hierarchy that provides the most commonly used overall description of the organization of memory in cognitive psychology. Figure 1 is my synthesis of Squire

David C. Rubin

david.rubin@duke.edu

1 Department of Psychology and Neuroscience, Duke University, Box 90086, Durham, NC 27708-0086, USA

2 Center on Autobiographical Memory Research, Aarhus University, 8000C Aarhus, Denmark
(1987) full hierarchy, with minor additions from Squire (2004). General limitations in hierarchies as scientific models are provided at the end of this section. A more detailed description of the problematic nature of the explicit versus implicit, which is the top level of this hierarchy, is provided in the last six paragraphs of the section on Explicit Processes.

There have been many attempts to reformulate and extend the range of categories Tulving considered. For instance, Brewer (1986) proposed categories of personal memory corresponding closely to the current use of autobiographical memory, autobiographical facts with no accompanying image, generic personal memory with an image but not a specific time or place, semantic memory, and generic perceptual memory. Larsen (1992) systematized his categories of autobiographical memory, autobiographical fact, narrative memory, and world knowledge with the concept of context replacing the concept of image in Brewer's system. The Toronto approach had categories of general semantic memory, personal semantics, and episodic memory, with personal semantics further divided into autobiographical facts, self-knowledge, repeated events, and autobiographically significant concepts (Renoult et al., 2012; also see Cabeza \& Moscovitch, 2013; Moscovitch, 1992). Underlying processes and neural substrates were proposed, whose importance varied with the categories. These include self-reflection, sensory-perceptual imagery, spatial/temporal features, emotional valence, and typical perspective. 


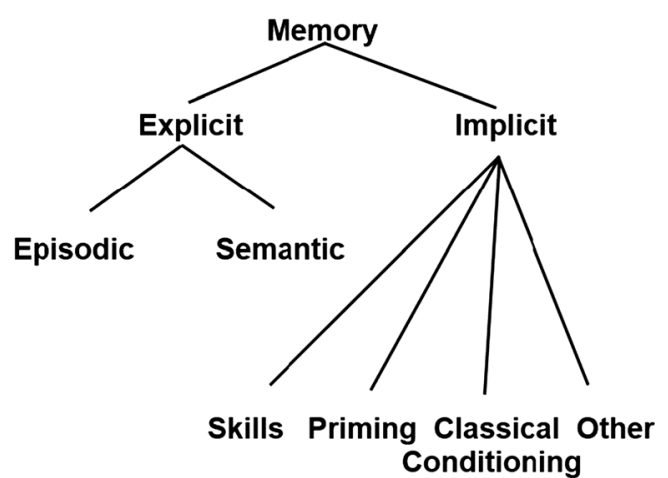

Fig. 1 A hierarchical organization of categories of memory (based on Squire, 1987, 2004)

Figure 2 is a set of three conceptually independent dimensions, which are needed to cover Tulving's episodic-semantic distinction and thus also the main categories of Squire's taxonomy. As discussed in detail in the section on Three Dimensions Based on Neurocognitive Processes, the dimensions are the following. Explicit versus implicit memory separates both episodic and semantic memory from implicit memory. Scene construction separates the specific event context needed for episodic memory from the context-free general knowledge needed for semantic memory. Self-reference selects memories of events involving the person remembering them, which is needed for Tulving's episodic-semantic distinction.

Scenes, which have a well-developed, specific, theoretical framework (Rubin, 2020a; Rubin, Deffler, et al., 2019; Rubin \& Umanath, 2015), described in the section on Scenes, do the conceptual work of image, context, sensory-perceptual imagery, spatial/temporal features, and typical perspective in the reformulations mentioned. Briefly, even if constructed from multiple encodings, a scene is remembered from a single location and thus locates the person recalling it in relation to the rest of the event supporting the sense of reliving, vividness, and belief, which help define autobiographical memories. In specifying an event beyond this, calendar time has been less useful than the contents that fill the scene and make it seem unique, such as who was present, what took place, and its role in surrounding events. Moreover, the empirical evidence indicates that the dating of events is not an inherent part of autobiographical memories but rather a distinct process (Friedman 1993, 2004, 2005; Thompson et al., 1996). Thus, unlike

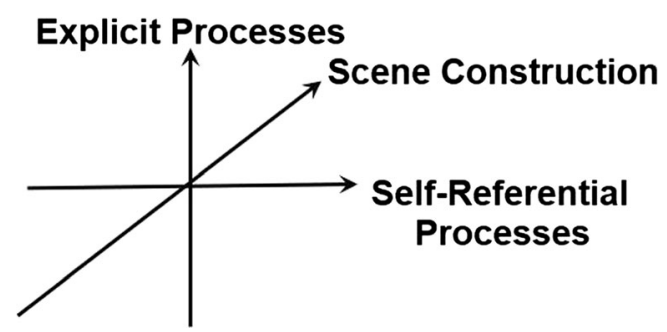

Fig. 2 A continuous dimensional organization of memory
Tulving's definition of episodic memory, which requires a real locus in space and time, in the dimensional model these can be phenomenological reports based on the construction of the memory, much like the incorrect judgement of prior presentation of nonpresented prototypes (Posner \& Keele, 1970).

The concepts of self, self-reflection, and self-reference in the reformulations mentioned are replaced with a broader reading of the narrative and social psychology literatures. Additionally, there is a critical examination of the implicit versus explicit memory distinction, which was not explicitly considered in these reformulations in detail because it is part of the episodic versus semantic distinction.

The dimensional model also addresses problems left unresolved by existing models of memory. A major one is that many well-documented, commonly studied memory phenomena do not fit into existing models of memory. Empirical research on human memory has outgrown the conceptual models that stimulated it. For example, concepts such as self-reference semantic memory (Kopelman et al., 1990; Prebble et al., 2013), non-self-reference episodic memories (Larsen, 1988), implicit self-reference memory including habitual ways of behaving (Hirst, 1994), and implicit-scene memory including déjà vu (Brown, 2003) fall outside the existing categories of the standard memory taxonomy. As a consequence, psychology frequently studies memory phenomena that do not fit into a generally agreed-upon conceptual space, leaving the field theoretically fragmented. To resolve this problem, and to provide a deeper theoretical rationale for our day-to-day research, I introduce a new organizational system for memory.

Consider two classic organizational systems for the basic concepts of a field of scientific study that could be used for memory. The beginnings of both are recorded from at least the time of the ancient Greeks, a time when there was little scientific theory to guide observation. Hierarchical organizations of life forms based on empirical observation aided in the theoretical development of biology. If an unidentified specimen was found, experts decided whether it belonged to an existing conceptual category. If the specimen required a new category, the experts modified the hierarchy to incorporate it. However, the hierarchy did not predict the existence of new life forms with particular properties - it just classified what was found or at best indicated possible missing links. One reason for this is that the properties specified in one category do not have to extend to other categories.

In contrast, for dimensional models, the properties extend across dimensions creating predictions about the properties of new categories. Consider the development of the periodic table of elements in chemistry. It had two dimensions based on observation, but they initially lacked a clear theoretical motivation, not unlike the current situation with theories of memory. The initial structure of the periodic table predated by a century the understanding of the atom now used to explain its 
structure. Though incomplete, the initial structure led to theories and to observations that tested those theories. The dimensional organization predicted categories for which no elements had yet been observed, what properties those elements would have, and under which conditions those elements would be observed. As theory and observation advanced together, more elements with specific properties were predicted to fill missing categories in the table, and more were found.

\section{Dimensions needed to locate episodic and semantic memory in a conceptual space}

\section{The dimensions chosen}

The selection of the three dimensions follows directly from Tulving's theory of episodic and semantic memory and from what is now known about memory from studies of behavior, neural processes in intact organisms, and in neuropsychological damage. One could argue that for many of the laboratory memory experiments of the last century, self-reference and the nature of the events were of little use and not examined empirically because recall was tested for non-self-referential words or syllables shown in the same color, font, and location, on the same memory drum or computer screen in the same room. Nonetheless, from Tulving's earliest introduction of episodic memory to his most recent papers, episodic memory was for the explicit memory of events that happened to the person recalling them, at one time and location (Tulving, 1972, 2002, 2005). Thus, by definition, episodic memory must be recalled as explicit memories, contain at least a minimal self-reference, and a minimal event memory.

\section{Continua versus categories}

The continuous dimensions of self-reference, scenes, and explicit processes are labeled with one extreme of their dimension in Fig. 2. For the present model, an underlying conceptual problem is that language favors categories, such as cups or bowls (Labov, 1973), self-reference or not, a scene or not, and explicit or implicit memory. There is no easy way to succinctly communicate in language about the continuous properties underlying such categories or the degree to which an exemplar fits a category. Continua require more of a prototype approach (Rosch, 1973), but we tend to have a Boolean combination of features for scientific categories. Thus, on one hand, I know of no convincing evidence that the three dimensions I use can be reduced to categories. On the other hand, using the psychological literature and conveying ideas in language requires the use of categories.

The three dimensions are continua. Individual memories vary in a continuous fashion along these dimensions at both the behavioral and neural level. For instance, people and objects vary on the dimension of self-reference, with some in the middle range of a continuum away from those at the extremes. Similarly, although memories may be considered explicit or implicit, many are not at the extremes and seem to drift across the boundary being in and out of consciousness (Mandler, 1994; Singer, 1966). Thus, the change to dimensions allows for the possibility of formal, quantitative models based on continuous variables that hierarchies lack. However, using the extremes of those continua as labels for categories simplifies communication and is necessary to maintain contact with the literature.

Viewed as dichotomies, the three dimensions combine to form eight categories in a nonhierarchical organization, as illustrated in Fig. 3. Each of the eight categories of memory has a high or low value on each of the three dimensions shown in Fig. 2, making comparisons to the other seven categories possible. This leads to theoretical and empirical issues that were not present in the standard hierarchical conception of the organization of memory. The dimensions specify relationships among all the categories and create new categories of memory, much as the early periodic table did for chemistry. I explore this alternative representation and show that it is an improvement both in its account of the empirical data and in its ability to generate interesting, novel, and tractable theoretical propositions. The attempt at turning fundamental concepts from Tulving's episodic-semantic distinction into dimensions also clarifies gaps in the literature about the concepts that are basic to understanding memory. Others I will cite have written about these problems, but the act of building a full account brings them all together and highlights the problems in new ways.

\section{Homogeneity versus heterogeneity}

I discuss all the dimensions in terms of their prototypical behavioral and neural properties. However, these properties vary

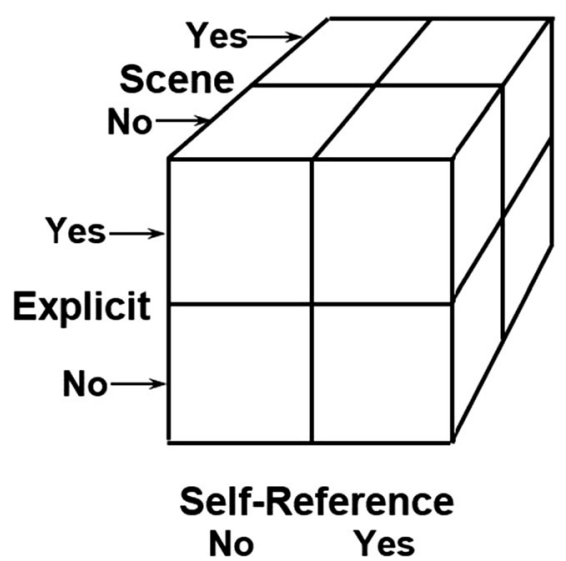

Fig. 3 A dimensional organization of memory divided into the dichotomous categories needed to account for Squire's major divisions of explicit versus implicit memory and episodic versus semantic memory 
across memories. Of greater theoretical importance, they may also vary systematically as a function of their values on the other dimensions. For instance, the neural basis of explicit versus implicit memory may differ with the degree to which the memory involves a scene or is self-relevant. Measuring the variation in the properties of one dimension as a function of the involvement of other dimensions may provide a way to describe and understand this heterogeneity. Although explaining heterogeneity is an extremely ambitious proposal, the dimensional approach at least provides a way to consider and study one source of this complexity.

\section{Three dimensions based on neurocognitive processes}

The descriptions of each of the three dimensions demonstrates the strengths and weaknesses of the underlying conceptual knowledge of memory needed to model episodic and semantic memory. Each dimension is evaluated in terms of having a coherent behavioral and neural description. Doing so clarifies limitations in the field's current understanding of its basic concepts and offers potential solutions. The approach is constructive in the tradition of Bartlett (1932) and Neisser $(1967,1976)$; memories are produced at recall, not stored in a fixed form which are later retrieved (Rubin, 2006).

\section{Self-reference}

The self-reference dimension, like the two dimensions that follow, has a deceptively simple definition. Self-reference indicates memories related to the person recalling them. The self-other dichotomy is needed for the episodic-semantic distinction. Here, it becomes a dimension ranging from the person remembering; to people who are very close to that person; to those with a common social group or ethnic, racial, or national identity; to those with minimal perceived relevance to the individual. The judgment of self-reference can be made by the person recalling the memory or an observer. Understanding the concept of self-reference, and related topics dealing with the self, has a large and growing literature that integrates traditional laboratory memory research with clinical, social, and other areas in psychology and neuroscience.

The self has long played a central role in psychology (Leary \& Tangney, 2012). To avoid the complexity of the concept of the self, psychology uses hyphenated selves (Allport, 1955). In these hyphenated terms, the self usually can be viewed as no more than a locus in space and time, which refers reflexively to the same physical entity, possibly at an earlier place and time. For instance, for the terms selfconcept or self-knowledge, people have a concept or knowledge of themselves in much the way they might have a concept or knowledge of an apple. The needed details of the self are particular to the theory describing self-concept or selfknowledge (e.g., Campbell et al., 2003; Hoyle, 2006). The same lack of details holds for the self of self-reference used here, and its inclusion as a dimension is an opportunity to explore the specific meanings that are important to memory research.

Narrative theories, which describe the life of an individual in terms of the organization of their autobiographical memories (Bruner, 1986; Habermas, 2019), are the main approach to self-reference in cognitive psychology. They include several related concepts including autobiographical reasoning, which is a "dimension of narrative focused on the subjective impact of the event on the self" (Habermas \& Bluck, 2000; McLean et al., 2017), narrative identity (Adler et al., 2016), narrative coherence (Reese et al., 2011), self-narrative focus (Rubin, Berntsen, et al., 2019) and self-concept focus (Rubin, 2020b), which measures the individual difference to make events central to one's identity, and self-concept clarity (Campbell et al., 1996), which assesses the extent to which beliefs about the self are clearly and confidently defined, internally consistent, and stable. These concepts are often used to compare the construction of past and future events (Boucher \& Scoboria, 2014; Rubin et al., 2019) and to trace the development over the lifespan of self-reference and its effects (Bauer, 2015; Habermas, \& Köber, 2015; Nelson \& Fivush, 2004).

The aspects of self-reference just reviewed depend on many neural systems. Nonetheless, neuroimaging studies of self-reference provide reasonably consistent findings. The most common areas to emerge in a variety of tasks in fMRI studies of self-reference are the medial prefrontal cortex and the posterior cingulate cortex (Denny et al., 2012; Kim \& Johnson, 2012; Moran et al., 2009; Morel et al., 2014) with damage to the medial prefrontal cortex removing selfreference effects (Philippi et al., 2012). Thus, a plausible underlying neural basis for this dimension exists.

\section{Scenes}

According to the theory of event memory (Rubin \& Umanath, 2015), an event memory is a mentally constructed scene. An event memory differs from an abstract idea and from a collection of objects and actions that could populate an event but that have no clear location relative to each other or to the person remembering them. As an example, consider a meal at a restaurant with a friend. Information that you might need to indicate you know what happened might include what you each ordered, the quality of the service, and the content of your conversation. Information that you might need to indicate you remember the meal as an event or an episodic memory might include where you sat in relation to your friend or in the restaurant as a whole. This spatial information would be 
relative to the mental location from which you recalled the meal.

As would be the case with drawing a scene, a mentally constructed scene is remembered from a single location. It may be from where you were at the time of the event, which is called a first-person or field perspective, or from an external vantage point, which is called a third-person or observer perspective (Nigro \& Neisser, 1983; Rice, \& Rubin, 2009; Robinson \& Swanson, 1993). The act of constructing a mental scene thereby locates the person recalling it in relation to the rest of the event (Berntsen \& Rubin, 2006; Butler et al., 2016; McIsaac \& Eich, 2002; Rice \& Rubin, 2011). In doing this, the act of constructing a scene forces a person to imagine himself or herself in one particular location (Rubin \& Umanath, 2015). Thus, the scene provides the sense of being located relative to the event during recall, which may or may not coincide with the location at encoding. Nonetheless, a single location supports experiencing a memory with a sense of reliving and vividness, which both add evidence that the event was actually witnessed and therefore should be believed (Rubin, Deffler, et al., 2019; Rubin \& Umanath, 2015). The scene also creates a locus in space and time for the person recalling the memory and thus helps support self-reference when it exists (Neisser, 1988).

The literature uses the terms scene and scene construction in a variety of ways. They can include measures as diverse as boundary extension, navigation, recall of isolated visual elements, and event segmentation (for a review, see Rubin \& Umanath, 2015). However, here scene and scene construction are restricted to the concept as it is described in terms of having an event memory - that is, an organized spatial layout that locates the person remembering relative to the rest of the scene. We have long known that visual imagery has strong effects on memory (Brewer, 1986; Rubin, 2006; Rubin et al., 2003); the crucial claim is that this is due in part to the spatial layout and not just the contents of the memory (Rubin, 2020a; Rubin, Deffler, et al., 2019; Rubin \& Umanath, 2015).

Constructed scenes can include actual witnessed events but also events about others and imagined events in the past and future. Such scenes all use similar processes, but vary on their degree of self-reference, effort needed for construction, and other factors (Rubin \& Umanath, 2015). The scene need not be remembered explicitly; in earlier work, we concentrated on explicit memories, but the dimensional model leaves a space for implicit scene memories.

The remembered scene, like a picture, is a single scene, even if it represents multiple encodings. Remembering the time of events is a distinct process from the construction of autobiographical memories (Friedman 1993, 2004, 2005; Thompson et al., 1996). Thus, unlike Tulving's definition of an episodic memory, a scene need not be for a single encoding but can be a summary or prototype (e.g., Posner \& Keele, 1970) of a series of repeated scenes that can be constructed as the same basic scene (e.g., the scene component of a generic, or future, meal at a restaurant with a friend).

The concept of a mentally constructed scene is based on evidence from studies of human neuropsychological damage. The loss of the ability to form a scene (e.g., to be able to imagine a prototypical beach on a sunny day) and the loss of explicit, but not implicit, autobiographical memory occur together in hippocampal amnesia (Hassabis et al., 2007; Maguire \& Mullally, 2013; Tulving, 2002). Moreover, people with damage earlier in the visual ventral stream, which is needed to construct scenes, have a rarer form of amnesia: visual-memory-deficit amnesia (Greenberg et al., 2005; Greenberg \& Rubin, 2003; Rubin \& Greenberg, 1998). This provides strong independent support for the role of scenes in event memory because the damage often spares the hippocampi, which, although necessary for scene construction, have many functions not involving visual processing. For either type of damage, the inability to construct a scene and amnesia co-occur. A similar claim cannot be made for any other property of memory (Rubin \& Umanath, 2015).

FMRI studies of vision and memory support the neuropsychological findings that the visual ventral stream is centrally involved in scene construction and event memory (e.g., Baldassano et al., 2016; Cabeza et al., 2004; Daselaar et al., 2008; Kanwisher \& Dilks, 2014; see Rubin \& Umanath, 2015, for a review). For instance, scenes activate the parahippocampal place area more than objects. For indoor scenes, parahippocampal place area remains activated even if objects are removed, leaving just the walls and floor (Epstein \& Kanwisher, 1998). The parahippocampal cortex is active for objects that evoke a strong sense of the surrounding space compared with ones that do not (Mullally \& Maguire, 2013). Thus, the neural basis of scene construction has strong converging evidence both from neuropsychological damage cases and from studies that measure activation in nonclinical individuals. Unlike the neuropsychological damage cases involving the loss of autobiographical memories, the scenes in the imaging studies often involve minimal self-relevance reinforcing that these two dimensions are independent except for scene memory locating the person remembering relative to the contents of the memory.

At a more general level, scenes stress an ecological approach that psychology minimized as it established itself as a science. In simplifying stimuli to understand complex problems of perception, memory, and neuroscience, researchers focused on isolated objects, considering the event or scene as a form of general context. However, for the intact, mobile organism, scenes and events are important levels of analysis on their own.

\section{Explicit processes}

The third dimension is explicit versus implicit processes. The idea that some knowledge is available to conscious 
introspection, whereas other knowledge can only be demonstrated in a procedural manner precedes the experimental study of memory. This idea is even reflected in our everyday language, such as recollection versus skill. That is, the basic phenomena to be explained were not invented by modern memory researchers. Moreover, from the earliest experimental studies, explicit and implicit processes have been intertwined. Ebbinghaus (1885/1964), for example, chose an implicit measure based on trials saved in relearning lists to measure gains in explicit recall.

In the modern memory literature, the explicit versus implicit dimension is generally conceptualized as a dichotomy. However, a continuous dimension is supported by concepts of consciousness in which memories can slowly develop and become fully conscious because of a strategic search or can remain below the level of consciousness and drift into conscious recollection in times of boredom, daydreaming, or mind wandering (Mandler, 1994; Seli et al., 2016; Singer, 1966; for a review see Berntsen, 2009). Consistent with this continuity, the judgment of explicit content often can be made on information that was initially recalled implicitly, but that later reached the level of consciousness.

There is an extensive theoretical literature within the last few decades on the explicit-implicit distinction. Given the goal of offering an alternative to Tulving's episodicsemantic distinction and Squire's hierarchy, which uses it, I focus on the declarative versus procedural (Squire, 1987), declarative versus nondeclarative (Squire, 2004, p. 173), or available-to-conscious-recollection (Squire, 2004, p. 171) aspects of this distinction and do not reconcile this conception with other alternatives in the memory literature. In particular, I do not include the intention-to-recall alternative, which investigates whether participants in experiments measuring implicit memory actually had an intention to recall making what the experimenter had planned as a measure of implicit memory into a measure of explicit memory. This became an issue in distinguishing relatively process-pure implicit memories in the laboratory from those tainted by explicit recall (for a review, see Roediger, 1990). Combining both the availableto-conscious-recollection and the intention-to-recall aspects into one scientific concept is not supported by the behavioral or neural data (Dew \& Cabeza, 2011), and the available-toconscious-recollection is more central to the main distinction needed for accounting for Tulving's episodic-semantic distinction.

The distinction between explicit and implicit memory, though widely accepted, has always been complex. For instance, Squire (1987, pp. 167-169) lists many divisions of memory closely related to the explicit versus implicit memory distinction that have developed in different theoretical frameworks. These include declarative versus procedural, knowing that versus knowing how, conscious recollection versus skills, memory with record versus memory without record, autobiographical versus perceptual, and representational versus dispositional. Squire also argued that it is hard to imagine a total separation of the neural systems for this distinction, because the later-evolving explicit memory processes depend in part on earlier-evolving implicit memory neural regions. Moreover, individual implicit categories in his hierarchy can sometimes be explicit. For instance, skills are often learned as explicit memories and become implicit with practice, and priming can have an explicit component.

Squire noted specific neural regions that were relevant to the implicit tasks he included. Squire's (2004, p. 173) Fig. 1 includes procedural skills and habits with a neural basis in the striatum, priming and perceptual learning with a neural basis in neocortex, simple classical conditioning of emotional responses with a neural basis the amygdala, and simple classical conditioning of skeletal responses with a neural basis in the cerebellum. The amygdala also had the more general role of being "able to modulate the strength of both declarative and nondeclarative memory." Moreover, there are neuropsychological cases that show that amygdala damage leaves no physiological evidence of the classical conditioning of emotional response, but leaves the conscious recollection of the contingencies. In contrast, hippocampal damage removes the conscious recollection, but leaves the physiological evidence of conditioning (Bechara et al., 1995).

Squire's placement of "simple classical conditioning" under implicit memory has also been contentious. Classical conditioning, with the possible addition of operant conditioning, can be viewed as a basic process involved in all memory. Squire (1994) viewed classical conditioning occurring both with and without awareness of the contingencies and provided evidence with control subjects, as well as individuals with amnesia, to support this view (Clark \& Squire, 1998, 1999). However, an opposing view is that, "there is no convincing evidence for conditioning in human subjects without awareness of the contingencies" (Boakes, 1989, p. 389; Brewer, 1974). Lovibond and Shanks (2002) reanalyzed data provided by Clark and Squire $(1998,1999)$ and agreed with Boakes's (1989) and Brewer's (1974) strong claim. This suggests that memories of conditioning are learned explicitly and should be classified as implicit or explicit depending on their recall, similar to skills performed implicitly after being that are learned explicitly (Lovibond et al., 2011; Weidemann et al., 2013).

In a review article on the "porous boundaries" between explicit and implicit memory, Dew and Cabeza (2011) conclude that the constructs used in the literature to distinguish between explicit and implicit memory have not yielded data consistent with the dichotomy. They conclude, "simple dichotomies between explicit and implicit memory are inadequate given the current state of the memory literature" (Dew \& Cabeza, 2011, p. 185). A possible contribution of the dimensional model is that because explicit memory is a heterogeneous dimension, systematic variation in it could be accounted 
for by other dimensions. However, this does not seem promising for the individual tasks Squire (1987) includes in his hierarchies.

Another problem for the explicit versus implicit dimension is that many implicit processes are more encapsulated in that they are specialized in terms of behavioral response (e.g., eye blink and skin conductance responses). Such processes are more localized neurally and might have a harder, and perhaps impossible, time entering explicit memory at recall. The dimensional model can contribute more to complex implicit memories that involve widespread systems that produce behaviors that are similar to, and that can more easily cross the boundary into, explicit memories at recall than for these more encapsulated processes.

Unlike the self-reference and scene construction dimensions, empirical support for a plausible neural basis for an explicit versus implicit distinction is lacking. The neural basis of the implicit versus explicit memory distinction would be clarified by either a well-developed account of the neural basis of consciousness or one of short-term or working memory that indicates the areas responsible for a memory being in the conscious now. However, neither currently exists. Rather, for the episodic versus semantic memory distinction, the dimensional model, and psychology in general, new constructs of implicit memory will be needed, or more likely, consistent with Dew and Cabeza (2011), a collection of processes that function to different extents in different situations.

\section{Categories of memory formed by combining all three dimensions}

As shown in Fig. 2, eight categories are formed when the three dimensions with end point of explicit versus implicit memory, scene versus non-scene, and self-reference versus non-selfreference are each made into dichotomies. The four explicit categories will be considered first in the following order: scene self-reference, scene non-self-reference, non-scene self-reference, and non-scene non-self-reference. After these four, explicit non-scene memory with and without selfreference will be considered again in a single section to make the discussion of loss in neuropsychological damage easier. For the four implicit categories, a different organization is more useful, with scene memory with and without selfreference and self-reference memory with and without scene memory discussed together.

Some of these categories contain well-studied forms of memory, whereas others place topics into the conceptual space of memory that have been excluded. Well-studied forms of memory in the conceptual space include episodic and semantic memory in explicit scene self-reference and explicit non-scene non-self-reference memory categories, respectively. Categories containing topics previously excluded from the conceptual space follow in the order in which they are presented in the rest of the section. Explicit scene non-selfreference memory includes real and fictional nonautobiographical events. Explicit non-scene self-reference memory includes autobiographical facts, semanticized forms of autobiographical memory, and the recently introduced personal semantics, which is an extension to Tulving's distinction between episodic and semantic memory. Implicit scene memory with and without self-reference includes recognizing people and objects as a function of their context, traversing familiar routes without explicit memory, and déjà vu. Implicit selfreference memory with and without scenes includes aspects of personality and other habitual ways of behaving, stress, worry and phobias.

\section{Explicit scene self-reference memory}

This category includes episodic memory and autobiographical memory in other classification systems. Thus, a loss of explicit self-reference memories results in amnesia, though some personal knowledge is typically preserved (see Cermak \& O'Connor, 1983; Hirst, 1994; Klein \& Lax, 2010; Tulving, 1993; Tulving et al., 1988; Warrington \& McCarthy, 1988).

For Tulving, episodic memories must be recalled explicitly by the person who experienced them. They also must be for an event remembered at a specific place and time; memories about objects free of their spatial and temporal context are semantic memories. Thus, in the dimensional model, episodic memories are explicit, self-related, scene memories; they fit into one category of the cube rather than being a major division in a hierarchy or their own category in Fig. 3. This is because episodic memories have numerous other properties, many of which can be viewed as independent processes (Tulving, 1983, p. 35, Table 3.1). When these are included, episodic memories become a subset of the category shown in Fig. 3. The most important of these properties for current purposes include the following. Episodic memories must come with a sense of reliving in the form of autonoetic consciousness or mental time travel (Rubin et al., 2003; Tulving, 1985). Such reliving usually depends on having a constructed scene at recall (Rubin \& Umanath, 2015). Episodic memories must be recalled voluntarily not involuntarily (i.e., in retrieval mode; Tulving, 1984, pp. 230-231). Episodic memories must be for a single occurrence (Tulving, 1972, 1983, 2002) and not a merging of information from similar occurrences, which is counter to the more process-oriented constructive approach to memory used to formulate dimensions (Bartlett, 1932; Neisser 1967, 1976; Rubin, 1988, 1995, 1998, 2006, 2014; Rubin \& Umanath, 2015).

The combination of these and the other additional properties into a single theoretical entity has long been questioned by leading memory theorists (Anderson \& Ross, 1980; McKoon et al., 1986; McKoon \& Ratcliff, 1979; and in most 
commentaries in Tulving, 1984; for a review, see Rubin \& Umanath, 2015). Even though many current researchers would not subscribe to all these properties, they still govern most studies of episodic memory (e.g., items presented once for explicit voluntary recall that are judged as remembered instead of known). These added properties also remain part of the theory of episodic memory. The use of dimensions with added restrictions for other properties of episodic memory, instead of a single combined concept of episodic memory, should help clarify both the behavior and neural basis of Tulving's concept of episodic memory and how it fits into the theoretical organization of memory in general.

\section{Explicit scene non-self-reference memory}

The dimensional organization allows real and fictional events that are not autobiographical to be considered in the non-selfreference explicit scene category, something that is missing from the current episodic versus semantic conception of memory in which episodic memories must have self-reference (Larsen, 1988; Pillemer et al., 2015; Rubin 1995). Larsen writes that Tulving's definition of episodic memory left such non-self-reference memories, including memories for events that were reported to the person recalling them, "in no-man's land, outside the taxonomy that came to guide memory research" (Larsen, 1988, p. 331). Moreover, people often have a sense of reliving for characters in an event with whom they identify or empathize (e.g., Rubin 1995). People can even remember another person's autobiographical memory as their own (Sheen et al., 2001). Much of social communication, cinema, and literature, including oral traditions, depends upon such abilities to assimilate explicit non-self-reference scene memories. In cases of neuropsychological damage, explicit non-self-reference scene memory includes patients who cannot imagine a generic scene and thus have a deficit in event memory (e.g., Hassabis et al., 2007).

\section{Explicit non-scene self-reference memory}

In an early paper, Brewer (1986) provided a taxonomy of autobiographical memories in which explicit nonimaginal (and thus non-scene) self-reference memories were autobiographical facts if they were for one occurrence or were selfschema if they repeated with variation. Prebble et al. (2013) made a similar point that "semanticized forms" of autobiographical memory are central to a sense of self. Renoult et al. (2012) added personal semantics, which includes autobiographical facts, self-knowledge, repeated events, and autobiographically significant concepts. In many theories, information related to an event, whether it is tied to the specific event or is semanticized from other memories, is combined in the process of remembering the event (Rubin, 2006, 2012; Rubin \& Umanath, 2015).

\section{Explicit non-scene non-self-reference memory}

This category includes semantic memory. Tulving wrote much less about the properties of semantic memory, except as a contrast to episodic memory, and so there is little to add here beyond noting its placement. As with episodic memory, it need not be the only type of memory in its cube.

\section{Explicit non-scene memory with and without self- reference produce semantic memory loss in neuro- psychological damage}

Such loss occurs in Korsakov's syndrome (Butters \& Cermak, 1986) and some cases of herpes simplex encephalitis (Wilson $\&$ Wearing, 1995). Moreover, consistent with the neural basis of scene memory, the damage involved in these cases extends beyond the medial temporal and ventral stream areas involved in scene memory. In addition, people with amnesia who lose scene memory often still retain self-reference. For instance, Clive Wearing retained a sense of things and people related to him even though the memories indicating this were often confabulations (Wilson \& Wearing, 1995). Thus, the dimensional approach helps to organize neuropsychological cases of memory loss in terms of dimensions developed to account for memory in general. Moreover, as will be discussed in the section on "implicit self-reference memory," the dimensional approach helps makes sense of the effects of implicit memory and social interactions in amnesia (Hirst, 1994). Combined with added processes, including, those for the individual senses, language, and narrative (Greenberg \& Rubin, 2003), it allows for a more systematic view of neuropsychological damage than does the episodic-semantic distinction.

\section{Implicit scene memory with and without self- reference}

Implicit scene memory includes effects in perception and action that are affected by their particular scene-based context. Depending on what is in the memory, it may have or not have self-reference, and the effects of difference between these two is not clear. Examples include recognizing people in, but not out, of their usual physical context (e.g., Mandler's 1980 example of not recognizing the butcher on the bus); knowing and adapting to what is coming next when walking a familiar route without any explicit memory of the route coming to mind, perhaps while attention is on a more demanding task. The dimensional model categorizes these examples as implicit scene memory and places them within an organization of memory that allows them to be compared with other phenomena in terms of well-studied dimensions.

Déjà vu is also classified as implicit scene memory. Consistent with the increase of familiarity and reliving of scene memory in explicit memory, in déjà vu there is a sense 
of familiarity and reliving without any explicit memory of a prior experience (Rubin \& Umanath, 2015). Brown (2003, 2004) reports several studies, based on both self-reports and analyses of participants' descriptions, in which the most common trigger of a déjà vu state is the similarity with an earlier scene. In a direct test of the claim that déjà vu depends on a similarity in scenes that is not explicitly noted, Cleary et al. (2009) matched the configural layout, but not the contents, of two scenes. One member of the pair of scenes was presented; the other was not. Only pairs involving presented scenes that were not recalled (i.e., not brought into explicit memory) were examined further. The scene of these pairs that was not presented had an increased probability of déjà vu states when compared with control scenes, and when these déjà vu states occurred, participants rated the familiarity of these nonpresented scenes as higher.

\section{Implicit self-reference memory with and without scenes}

Implicit and explicit non-self-reference memories have major literatures in laboratory studies of words, and explicit selfreference memories has a major literature in autobiographical memory. Implicit self-reference memories do not. Whether all implicit self-reference memories differ from implicit non-selfreference memories in theoretically interesting ways is an open question, but at first glance, implicit self-reference memory looks like a major component of personality and other habitual ways of behaving. Considering them this way would help to integrate individual differences variables related to personality into an organizational scheme for memory, providing a framework to examine their contributions on the same level of analysis as other forms of memory. In terms of clinical phenomena, implicit self-reference memories might be considered as underlying aspects of anxiety disorders when they produce negative emotions. This relationship could occur for implicit memories of scenes including posttraumatic stress disorder symptoms related to traumatic events and worry related to possible future events, and for non-scene isolated objects in phobias.

Hirst (1994) developed much more detailed functions for what I am calling implicit self-reference memories, which he supported empirically by studies and observations of amnesics. He notes that amnesics have a sense of self and selfreference that not only endured the onset of deficits in explicit memory but that also changed to adapt to their amnesia without the aid of post onset explicit memory. He notes that although implicit memories may not affect the life narrative or explicit recall of memories, they clearly impact actions and self-construal. For instance, H. M. could not explicitly recall the death of his parents, but knew implicitly that he was a person without parents and acted accordingly. His own patients often could not recall their marriages, divorces, illnesses, and children's births, but acted in a way that indicated they had an implicit sense of self that reflected the reality such events produced. For instance, he describes a patient who recalled spared explicit memories from his early job working in a lumber camp but had the demeanor and dress of the executive he later became but did not recall explicitly. He stresses that such implicit contributions also depend on social interactions and thus a socially constructed self at the local and collective level. It is reasonable to assume these analyses apply to people with normal forgetting, though excluding explicit contributions may be more difficult.

\section{Summary of categories of memories}

The automatic, mechanical creation of categories with properties that fit into a conceptually defined space is a major advantage of the dimensional approach. In contrast, hierarchies describe and organize categories that have already been formed and do not require properties to extend beyond each category. A new category that allows phenomena to be understood is the most interesting outcome of a dimensional approach. However, even showing that some created categories are not different in interesting ways from those adjacent to them is a way of demonstrating a local generalization across theoretically important dimensions.

In this process, the continua organize the categories into a single space and thus allow contact with the category-based existing literature. In addition, because individual memories vary in a continuous fashion with values in the middle of their range as well as the extremes used to create the categories, consideration of values away from the extreme and quantitative models based on continuous variables are possible.

\section{Limitations}

A dimensional organization is proposed as an alternative to the hierarchical organization now used for memory. Like the episodic-semantic distinction, and Squire's hierarchy in which it is embedded, it argues that memory can be divided into subtypes with behavioral properties and neural substrates. Like these theoretical statements, it is not intended to solve all problems in memory research. The limitations are longstanding; Squire $(1987,2004)$ discussed some of these issues as complications to the hierarchical structure, while stressing that memory is not a unitary concept.

The concepts of short-term and working memory were not considered because Tulving's theory of episodic and semantic memory does not include them, though he did make some use of them. In his earliest paper on episodic memory, Tulving notes that the term working memory occurs in about 25 categories of memory in a collection of book chapters (Tulving, 1972, p. 382). In a recent paper, he notes that the amnesic KC 
has a normal short-term memory (Tulving, 2002, p. 13). In his book, he discusses a working versus reference memory distinction in the animal literature that is close to the episodic versus semantic memory distinction and not to working memory as it used in the human literature (Tulving, 1983, pp. 118120). Nonetheless, the concepts of short-term and working memory are close to James's (1890) concept of the conscious now and thus can be considered as indications of information entering explicit memory. In the process-focused, constructive approach used here, the concept of the conscious now can be viewed as part of the processes of attention (Rubin, 2012, pp. 24-26). Thus, based on Tulving's theory and the constructive process approach of the dimensional model, the theoretical distinction between short-term and working memory and long-term memory was also not addressed here.

The development and interaction of the three dimensions over the lifespan remains to be examined in the dimensional model, though from what is known the dimensions have different patterns of development (Bauer, 2007; Rubin, 2012; Rubin \& Umanath, 2015). Using language use as a measure of development, self-reference is present when the first-person pronoun and the possessive "mine" are used with more complex aspects of self-reference developing into adolescence (Bohn \& Berntsen, 2008; Habermas \& Bluck, 2000; Nelson $\&$ Fivush, 2004). Similarly, explicit memory is present when speech about the past begins. Earlier development can be found with nonlinguistic measures. Less is known about the more recent construct of scenes used here, but it is clear that young children act on the layout of their environment, are sensitive to changes to it, and are cued by it to talk spontaneously about what happened earlier when a scene is revisited (e.g., Hjuler et al., 2021; Sonne et al., 2020).

In addition, I limited the dimensions to account for the major distinctions in the episodic-semantic distinction and Squire's hierarchy. For other purposes, such as extending these ideas to autobiographical memory (Rubin, 2019), different dimensions could be used along with or instead of the ones considered here. In particular, I did not include the intentionto-recall aspect of explicit memory used in distinguishing implicit memories in the laboratory. A dimension based on the processes of intention or volition to recall might be considered, which when crossed with other dimensions, would provide categories for involuntary and voluntary memories (Berntsen, 2009). An emotional intensity dimension might also be considered. A valence dimension would be more difficult to justify because the effects of valence are not as robust as those of emotional intensity, and because positive versus negative valence are not extremes of a single dimension (Bradley et al., 1992; Talarico et al., 2004). Rather emotional intensity might have to be divided into two dimensions, one for positive and one for negative emotions. Such dimensions might be especially relevant for the memory related aspects of clinical disorders. In addition, the growing research area of future events, which owes much to Tulving, research on imagined events, which provide an important contrast to future events, and counterfactuals, which can help understand both of these areas could provide another dimension that would clarify the model.

\section{Summary}

I am certain that I have not provided a detailed analysis of all relevant theoretical issues and that, for any specific issue, readers could provide improvements in their areas of expertise. Moreover, if changes in definition of terms or other modifications were made, the episodic-semantic distinction might be improved. Nonetheless, I claim that the dimensional model is a useful alternative to the episodic-semantic distinction that Tulving presented nearly a half century ago. The dimensional model generates novel hypotheses for research, and it provides a better a summary of what is known and a better assessment of the strengths and weaknesses of that knowledge.

The dimensional model demonstrates that dimensions have clear advantages over hierarchies as organizational structures for memory. The attempt to clearly describe the dimensions required a critical examination of the basic distinctions used in memory research. Moreover, each dimension's interaction with all other dimensions must be considered, which suggests new categories of memory and places them in a theoretical relation to other categories.

The new categories of memory solve a real problem in current theory by providing a much more complete context for memory research. In particular, it provides a home for many homeless categories of memory, which were excluded from the traditional taxonomies of memory. The contents I suggest for some of these new categories have already been studied. However, the content may be better understood when placed into a dimensional structure that describes other memory research that provides a theoretical framework beyond what has been developed for them in isolation. These new categories include non-self-reference explicit scene memories which provides a home for fiction and other people's memories; self-reference implicit scene memories which provides a home for déjà vu; and self-reference implicit non-scene memories, which provides a home for personality, habit, and phobias. The last category could also provide a way to increase the understanding of individual differences in memory. For all these advantages, a dimensional organization provides a strong alternative characterization of memory and a critical examination of the basic concepts of memory research in general and the episodic-semantic distinction in particular.

Author note I wish to thank Dorthe Berntsen, Kaitlyn Brodar, Roberto Cabeza, Simon Davis, Emmaline Drew, Tobias Egner, Kristiana 
Gambuti, Shana Hall, Kevin LaBar, Elizabeth Marsh, the Memory at Duke Group, and the North Carolina Cognition Conference for comments and grant DNRF89 to the Center on Autobiographical Memory Research, Aarhus University.

\section{References}

Adler, J. M., Lodi-Smith, J., Philippe, F. L., \& Houle, I. (2016). The incremental validity of narrative identity in predicting well-being: A review of the field and recommendations for the future. Personality and Social Psychology Review, 20(2), 142-175. https://doi.org/10.1177/1088868315585068

Allport, G. W. (1955). Becoming: Basic considerations for a psychology of personality. New Haven: Yale University Press.

Anderson, J. R., \& Ross, B. H. (1980). Evidence against a semanticepisodic distinction. Journal of Experimental Psychology: Human Learning and Memory, 6(5), 441-466. https://doi.org/10.1037/ 0278-7393.6.5.441

Baldassano, C., Esteva, A., Fei-Fei, L., \& Beck, D. M. (2016). Two distinct scene-processing networks connecting vision and memory. eNeuro, 3(5), Article ENEURO.0178-16.2016. https://doi.org/10. 1523/ENEURO.0178-16.2016

Bauer, P. J. (2007). Remembering the times of our lives: Memory in infancy and beyond. Mahwah, CT: Erlbaum.

Bauer, P. J. (2015). A complementary processes account of the development of childhood amnesia and a personal past. Psychological Review, 122, 204-231. https://doi.org/10.1037/a0038939

Bartlett, F. C. (1932). Remembering: A study in experimental and social psychology. London: Cambridge University Press.

Bechara, A., Tranel, D., Damasio, H., Adolphs, R., Rockland, C., \& Damasio, A. R. (1995). Double dissociation of conditioning and declarative knowledge relative to the amygdala and hippocampus in humans. Science, 269(5227), 1115-1118. https://doi.org/10. $1126 /$ science. 7652558

Berntsen, D. (2009). Involuntary autobiographical memories: An introduction to the unbidden past. Cambridge: Cambridge University Press.

Berntsen, D., \& Rubin, D. C. (2006). The centrality of event scale: A measure of integrating a trauma into one's identity and its relation to post-traumatic stress disorder symptoms. Behaviour Research and Therapy, 44, 219-231. https://doi.org/10.1016/j.brat.2005.01.009

Boakes, R. A. (1989). How one might find evidence for conditioning in adult humans. In T. Archer \& L.-G. Nilsson (Eds.), Aversion, avoidance and anxiety: Perspectives on learning and memory (pp. 381402). Hillsdale, NJ: Erlbaum.

Bohn, A., \& Berntsen, D. (2008). Life story development in childhood: The development of life story abilities and the acquisition of cultural life scripts from late middle childhood to adolescence. Developmental Psychology, 44(4), 1135-1147. https://doi.org/10. 1037/0012-1649.44.4.1135

Boucher, C. M., \& Scoboria, A. (2014). Reappraising past and future transitional events the effects of mental focus on present perceptions of personal impact and self-relevance. Journal of Personality, 83(4), 361-375. https://doi.org/10.1111/jopy.12109

Bradley, M. M., Greenwald, M. K., Petry, M. C., \& Lang, P. J. (1992). Remembering pictures: Pleasure and arousal in memory. Journal of Experimental Psychology: Learning, Memory, \& Cognition, 18(2), 379-390. https://doi.org/10.1037//0278-7393.18.2.379

Brewer, W. F. (1974). There is no convincing evidence for operant or classical conditioning in adult humans. In W. B. Weimer \& D. S. Palermo (Eds.), Cognition and the symbolic processes (pp. 1-42). Hillsdale, NJ: Erlbaum.
Brewer, W. F. (1986). What is autobiographical memory? In D. C. Rubin (Ed.), Autobiographical memory (pp. 25-49). Cambridge: Cambridge University Press.

Brown, A. S. (2003). A review of the déjà vu experience. Psychological Bulletin, 129(3), 394-413. https://doi.org/10.1037/0033-2909.129. 3.394

Brown, A. S. (2004). The déjà vu experience. New York: Psychology Press.

Bruner, J. S. (1986). Actual minds, possible worlds. Cambridge, MA: Harvard University Press.

Butler, A. C., Rice, H. J., Wooldridge, C. L., \& Rubin, D. C. (2016). Visual imagery in autobiographical memory: The role of repeated retrieval in shifting perspective. Consciousness \& Cognition, 42, 327-253. https://doi.org/10.1016/j.concog.2016.03.018

Butters, N., \& Cermak, L. S. (1986). A case study of the forgetting of autobiographical knowledge: Implications for the study of retrograde amnesia. In D. C. Rubin (Ed.), Autobiographical memory (pp. 253-272). Cambridge: Cambridge University Press.

Cabeza, R., \& Moscovitch, M. (2013) Memory systems, processing modes, and components: Functional neuroimaging evidence. Perspectives on Psychological Science 8(1), 49-55. https://doi.org/ 10.1177/1745691612469033

Cabeza, R., Prince, S. E., Daselaar, S. M., Greenberg, D. L., Budde, M., Dolcos, F., LaBar, K. S., \& Rubin, D. C. (2004). Brain activity during episodic retrieval of autobiographical and laboratory events: An fMRI study using a novel photo paradigm. Journal of Cognitive Neuroscience, 16(9), 1583-1594. https://doi.org/10.1162/ 0898929042568578

Campbell, J. D., Assanand, S., \& Di Paula, A. (2003). The structure of the self-concept and its relation to psychological adjustment. Journal of Personality, 71(1), 115-140. https://doi.org/10.1111/1467-6494. t01-1-00002

Campbell, J. D., Trapnell, P. D., Heine, S. J., Katz, I. M., Lavallee, L. I., \& Lehman, D. R. (1996). Self-concept clarity: Measurement, personality correlates, and cultural boundaries. Journal of Personality and Social Psychology, 70(1), 141-156. https://doi.org/10.1037/ 0022-3514.70.1.141

Cermak, L. S., \& O'Connor, M. (1983). The anterograde and retrograde retrieval ability of a patient with amnesia due to encephalitis. Neuropsychologia, 21(3), 213-234. https://doi.org/10.1016/00283932(83)90039-8

Clark, R. E., \& Squire, L. R. (1998). Classical conditioning and brain systems: The role of awareness. Science, 280, 77-81. https://doi.org/ 10.1126/science. 280.5360 .77

Clark, R. E., \& Squire, L. R. (1999). Human eyeblink classical conditioning: Effects of manipulating awareness of the stimulus contingencies. Psychological Science, 10(1), 14-18. https://doi.org/10. 1111/1467-9280.00099

Cleary, A. M., Ryals, A. J., \& Nomi, J. S. (2009). Can déjà vu result from similarity to a prior experience? Support for the similarity hypothesis of déjà vu. Psychonomic Bulletin \& Review, 16(6), 1082-1088. https://doi.org/10.3758/PBR.16.6.1082

Daselaar, S. M., Rice, H. J., Greenberg, D. L., Cabeza, R., LaBar, K. S., \& Rubin, D. C. (2008). The spatiotemporal dynamics of autobiographical memory: Neural correlates of recall, emotional intensity, and reliving. Cerebral Cortex, 18, 217-229. https://doi.org/10.1093/ cercor/bhm048

Denny, B. T., Kober, H., Wager, T. D., Ochsner, K. N. (2012). A metaanalysis of functional neuroimaging studies of self- and other judgments reveals a spatial gradient for mentalizing in medial prefrontal cortex. Journal of Cognitive Neuroscience, 24(8), 1742-1752. https://doi.org/10.1162/jocn a 00233

Dew, I. T. Z., \& Cabeza, R. (2011). The porous boundaries between explicit and implicit memory: Behavioral and neural evidence. Annals of the New York Academy of Science, 24(8), 174-190. https://doi.org/10.1111/j.1749-6632.2010.05946.x 
Ebbinghaus, H. (1964). Memory: A contribution to experimental psychology (H. A. Ruger \& C. E. Bussenius, Trans.). New York: Dover. (Original work published 1885)

Epstein, R., \& Kanwisher, N. (1998). A cortical representation of the local visual environment. Nature, 392, 598-601. https://doi.org/10. $1038 / 33402$

Friedman, W. J. (1993). Memory for the time of past events. Psychological Bulletin, 113(1), 44-66. https://doi.org/10.1037/ 0033-2909.113.1.44

Friedman, W. J. (2004). Time in autobiographical memory. Social Cognition, 22(5), 605-621. https://doi.org/10.1521/soco.22.5.591. 50766

Friedman, W. J. (2005). Developmental and cognitive perspectives on humans' sense of the times of past and future events. Learning and Motivation, 36(2), 145-158. https://doi.org/10.1016/j.lmot. 2005.02.005

Greenberg, D. L., Eacott, M. J., Brechin, D., \& Rubin, D. C. (2005). Visual memory loss and autobiographical amnesia: A case study. Neuropsychologia, 43(10), 1493-1502. https://doi.org/10.1016/j. neuropsychologia.2004.12.009

Greenberg, D. L. \& Rubin, D. C. (2003). The neuropsychology of autobiographical memory. Cortex, 39(4/5), 687-728. https://doi.org/10. 1016/S0010-9452(08)70860-8

Habermas, T. (2019). Emotion and narrative: Perspectives in autobiographical storytelling. Cambridge, U.K.: Cambridge University Press.

Habermas, T. \& Bluck, S. (2000). Getting a life: The emergence of the life story in adolescence. Psychological Bulletin, 126(5), 748-769. https://doi.org/10.1037/0033-2909.126.5.748

Habermas, T \& Köber C. (2015). Autobiographical reasoning in life narratives buffers the effect of biographical disruptions on the sense of self-continuity. Memory, 23(5), 664-674. https://doi.org/10. 1080/09658211.2014.920885

Hassabis, D., Kumaran, D., Vann, S., \& Maguire, E. (2007). Patients with hippocampal amnesia cannot imagine new experiences. Proceedings of the National Academy of Sciences of the United States of America, 104(5), 1726-1731. https://doi.org/10.1073/ pnas.0610561104

Hirst, W. (1994). The remembering self in amnesics. In U. Neisser \& R. Fivush (Eds.), The remembering self: Construction and accuracy in the self-narrative. Cambridge, UK. Cambridge University Press

Hjuler, T., Sonne, T., Kingo, O. S., Berntsen, D., \& Krøjgaard, P. (2021). Real-time assessment of looking time at central environmental cues for spontaneous recall in 35-month-olds. Cognitive Development, 57. Advance online publication. https://doi.org/10.1016/j.cogdev. 2020.100995

Hoyle, R. H. (2006). Self-esteem and self-knowledge. In M. H. Kernis (Ed.), Self-esteem issues and answers: A sourcebook on current perspectives (pp. 208-215). New York: Psychology Press.

James, W. (1890). The principles of psychology (Vols. 1-2). New York: Henry Holt.

Kanwisher, N., \& Dilks, D. D. (2014). The functional organization of the ventral visual pathway in humans. In J. S. Werner \& L. M. Chalupa (Eds.), The new visual neurosciences (pp. 733-746). Cambridge, MA: MIT Press.

Kim, K., \& Johnson, M. K. (2012). Extended self: Medial prefrontal activity during transient association of self and objects. Social Cognitive and Affective Neuroscience, 7(2), 199-207. https://doi. org/10.1093/scan/nsq096

Klein, S. B., \& Lax, M. L. (2010). The unanticipated resilience of trait self-knowledge in the face of neural damage. Memory, 18(8), 918 948. https://doi.org/10.1080/09658211.2010.524651

Kopelman, M. D., Wilson, B. A., \& Baddeley, A. D. (1990). The autobiographical memory interview. Thames Valley Test Company; Bury St Edmunds, England.
Labov, W. (1973). The boundaries of words and their meanings. In C.-J. Bailey \& R. W. Shuy (Eds.), New ways of analyzing variation in English (pp. 340-371). Washington, DC: Georgetown University Press.

Larsen, S. F. (1988). Remembering without experiencing: Memory for reported events. In U. Neisser \& E. Winograd (Eds.), Remembering reconsidered: Ecological and traditional approaches to the study of memory (pp. 326-355). Cambridge: Cambridge University Press.

Larsen, S. E. (1992). Personal context in autobiographical and narrative memories. In M. A. Conway, D. C, Rubin, H. Spinnler, \& W. A. Wagenaar (Eds.), Theoretical perspectives on autobiographical memory (pp. 53-71). Dordrecht, The Netherlands: Kluwer.

Leary, M. R., \& Tangney, J. P. (2012). The self as an organizing construct in the behavioral and social sciences. In M. R. Leary \& J. P. Tangney (Eds.), Handbook of self and identity (2nd ed., pp. 3-14). New York: Guilford Press.

Lovibond, P. F., Liu, J. C. J., Weidemann, G., \& Mitchell, C. J. (2011). Awareness is necessary for differential trace and delay eyeblink conditioning in humans. Biological Psychology, 87(3), 393-400. https://doi.org/10.1016/j.biopsycho.2011.05.002

Lovibond, P. F., \& Shanks D. R. (2002). The role of awareness in Pavlovian conditioning: Empirical evidence and theoretical implications. Journal of Experimental Psychology: Animal Behavior Processes, 28(1), 3-26. https://doi.org/10.1037/0097-7403.28.1.3

Maguire, E. A., \& Mullally, S. L. (2013). The hippocampus: A manifesto for change. Journal of Experimental Psychology: General, 142(4), 1180-1189. https://doi.org/10.1037/a0033650

Mandler, G. (1980). Recognizing: The judgment of previous occurrence. Psychological Review, 87(3), 252-271. https://doi.org/10.1037/ 0033-295X.87.3.252

Mandler, G. (1994). Hypermnesia, incubation, and mind popping: On remembering without really trying. In C. Umilta \& M. Moscovitch (Eds.), Attention and performance: Conscious and unconscious information processing (pp. 3-33). Cambridge: MIT Press.

McIsaac, H. K., \& Eich, E. (2002). Vantage point in episodic memory. Psychonomic Bulletin \& Review, 9, 146-150. https://doi.org/10. 3758/BF03196271

McKoon, G., \& Ratcliff, R. (1979). Priming in episodic and semantic memory. Journal of Verbal Learning and Verbal Behavior, 18(4), 463-480. https://doi.org/10.1016/S0022-5371(79)90255-X

McKoon, G., Ratcliff, R., \& Dell, G. S. (1986). A critical evaluation of the semantic-episodic distinction. Journal of Experimental Psychology: Learning, Memory, and Cognition, 12(2), 295-306. https://doi.org/10.1037/0278-7393.12.2.295

McLean, K. C., Pasupathi, M., Greenhoot, A. F., \& Fivush, R. (2017). Does intra-individual variability in narration matter and for what? Journal of Research in Personality, 69, 55-66. https://doi.org/10. 1016/j.jrp.2016.04.003

Moran, J. M., Heatherton, T. F., \& Kelley, W. M. (2009). Modulation of cortical midline structures by implicit and explicit self-relevance evaluation. Social Neuroscience, 4(3), 197-211. https://doi.org/10. 1080/17470910802250519

Morel, N., Villain, N., Rauchs, G., Gaubert, M., Piolino P., Landeau, B., Mézenge, F., Desgranges, B., Eustache, F., \& Chételat G. (2014). Brain activity and functional coupling changes associated with selfreference effect during both encoding and retrieval. PLOS ONE, 9(3), Article e90488. https://doi.org/10.1371/journal.pone.0090488

Moscovitch, M. (1992). Memory and working-with-memory: A component process model based on modules and central systems. Journal of Cognitive Neuroscience, 4(3), 257-267. https://doi.org/10.1162/ jocn.1992.4.3.257

Mullally, S. L., \& Maguire, E. A. (2013). Exploring the role of space defining objects in constructing and maintaining imagine scenes. Brain and Cognition, 82(1), 100-107. https://doi.org/10.1016/j. bandc.2013.02.013 
Neisser, U. (1967). Cognitive psychology. Englewood Cliffs: PrenticeHall.

Neisser, U. (1976). Cognition and reality: Principles and implications of cognitive psychology. New York: Freeman

Neisser, U. (1988). Five kinds of self-knowledge. Philosophical Psychology, 1(1), 35-59. https://doi.org/10.1080/ 09515088808572924

Nelson, K., \& Fivush, R. (2004). The emergence of autobiographical memory: A social cultural developmental theory. Psychological Review, 111(2), 486-511. https://doi.org/10.1037/0033-295X.111. 2.486

Nigro, G., \& Neisser, U. (1983). Point of view in personal memories. Cognitive Psychology, 15(4), 467-482. https://doi.org/10.1016/ 0010-0285(83)90016-6

Philippi, C. L., Duff, M. C., Denburg, N. L., Tranel, D., \& Rudrauf, D. (2012). Medial PFC damage abolishes the self-reference effect. Journal of Cognitive Neuroscience 24(2), 475-481. https://doi.org/ $10.1162 /$ jocn a 00138

Pillemer, D., Steiner, K., Kuwabara, K., Thomsen, D. K., \& Svob, C. (2015). Vicarious memories. Consciousness and Cognition, 36, 233-245. https://doi.org/10.1016/j.concog.2015.06.010

Posner, M. J., \& Keele, S. (1970). Retention of abstract ideas. Journal of Experimental Psychology, 83(2, Pt. 6), 304-308. https://doi.org/10. 1037/h0028558

Prebble, S. C., Addis, D. R., \& Tippett, L. J. (2013). Autobiographical memory and sense of self. Psychological Bulletin, 139(4), 815-840. https://doi.org/10.1037/a0030146

Reese, E., Haden, C. A., Baker-Ward, L., Bauer, P., Fivush, R., \& Ornstein, P. A. (2011). Coherence of personal narratives across the lifespan: A multidimensional model and coding method. Journal of Cognition and Development, 12(4), 424-462. https://doi.org/10. 1080/15248372.2011.587854

Renoult, L., Davidson, P. S. R., Palombo, D. J., Moscovitch, M., \& Levine, B. (2012). Personal semantics: At the crossroads of semantic and episodic memory. Trends in Cognitive Sciences, 16(11), 550 558. https://doi.org/10.1016/j.tics.2012.09.003

Rice, H. J., \& Rubin, D. C. (2009). I can see it both ways: First- and thirdperson visual perspectives at retrieval. Consciousness and Cognition, 18(4), 877-890. https://doi.org/10.1016/j.concog.2009. 07.004

Rice, H., \& Rubin, D. (2011). Remembering from any angle: The flexibility of visual perspective during retrieval. Consciousness and Cognition, 20(3), 568-577. https://doi.org/10.1016/j.concog.2010. 10.013

Robinson, J. A., \& Swanson, K. L. (1993). Field and observer modes of remembering. Memory, 1(3), 169-184. https://doi.org/10.1080/ 09658219308258230

Roediger, H. L. (1990). Implicit memory: Retention without remembering. American Psychologist, 45(9), 1043-1056. https://doi.org/10. 1037//0003-066x.45.9.1043

Rosch, E. H. (1973). Natural categories. Cognitive Psychology, 4(3), 328-350. https://doi.org/10.1016/0010-0285(73)90017-0

Rubin, D. C. (1988). Go for the skill. In U. Neisser \& E. Winograd (Eds.), Remembering reconsidered: Ecological and traditional approaches to the study of memory (pp. 374-382). Cambridge: Cambridge University Press.

Rubin, D. C. (1995). Memory in oral traditions: The cognitive psychology of epic, ballads, and counting-out rhymes. New York: Oxford University Press.

Rubin, D. C. (1998). Beginnings of a theory of autobiographical remembering. In C. P. Thompson, D. J. Herrmann, D. Bruce, J. D. Reed, D. G. Payne, \& M. P. Toglia (Eds.), Autobiographical memory: Theoretical and applied perspectives (pp. 47-67). Mahwah, NJ: Erlbaum.
Rubin, D. C. (2006). The basic-systems model of episodic memory. Perspectives on Psychological Science, 1(4), 277-311. https://doi. org/10.1111/j.1745-6916.2006.00017.x

Rubin, D. C. (2012). The basic system model of autobiographical memory. In D. Berntsen \& D. C. Rubin. (Eds.). Understanding autobiographical memory: Theories and approaches (pp. 11-32). Cambridge: Cambridge University Press.

Rubin, D. C. (2014). Schema driven construction of future autobiographical traumatic events: The future is much more troubling than the past. Journal of Experimental Psychology: General, 143, 612-630.

Rubin, D. C. (2019). Placing autobiographical memory in a general memory organization. In J. H. Mace (Ed.), The organisation and structure of autobiographical memory. Oxford University Press.

Rubin, D. C. (2020a). The ability to recall scenes is a stable individual difference: Evidence from autobiographical remembering. Cognition. Advance online publication. https://doi.org/10.1016/j. cognition.2019.104164

Rubin, D. C. (2020b). Self-concept focus: A tendency to perceive autobiographical events as centrality to identity. Journal of Applied Research in Memory and Cognition, 9(4), 576-586. https://doi. org/10.1016/j.jarmac.2020.06.001

Rubin, D. C., Berntsen, D., Deffler, S., \& Brodar, K. (2019). Selfnarrative focus in autobiographical events: The effect of time, emotion and individual differences. Memory \& Cognition, 47(1), 63-75. https://doi.org/10.3758/s13421-018-0850-4

Rubin, D. C., Deffler, S, \& Umanath, S (2019). Scenes enable a sense of reliving: Implications for autobiographical memory. Cognition, 183, 44-56.

Rubin, D. C. \& Greenberg, D. L. (1998). Visual memory-deficit amnesia: A distinct amnesic presentation and etiology. Proceedings of the National Academy of Sciences, 95, 5413-5416.

Rubin, D. C., Schrauf, R. W., \& Greenberg D. L. (2003). Belief and recollection of autobiographical memories. Memory \& Cognition, 31, 887-901. https://doi.org/10.3758/BF03196443

Rubin, D. C., \& Umanath, S. (2015). Event memory: A theory of memory for laboratory, autobiographical, and fictional events. Psychological Review, 122(1), 1-23. https://doi.org/10.1037/a0037907

Seli, P., Risko, E. F., \& Smilek, D. (2016). On the necessity of distinguishing between unintentional and intentional mind wandering. Psychological Science, 27, 685-691.

Sheen, M., Kemp, S., \& Rubin, D. C. (2001). Twins dispute memory ownership: A new false memory phenomenon. Memory \& Cognition, 29, 779-788. https://doi.org/10.3758/BF03196407

Singer, J. L. (1966). Daydreaming: An introduction to the experimental study of inner experience. New York: Random House.

Sonne, T., Kingo, O. S., Berntsen, D., \& Krøjgaard, P. (2020). Noting a difference: change in social context prompts spontaneous recall in 46-month-olds, but not in 35-month-olds. Psychological Research. Advance online publication. https://doi.org/10.1007/s00426-02001310-7

Squire, L. R. (1987). Memory and brain. New York: Oxford University Press.

Squire, L. R. (1994). Declarative and nondeclarative memory: Multiple brain systems supporting learning and memory. In D. L. Schacter \& E. Tulving (Eds.), Memory systems 1994 (pp. 203-231). Cambridge, MA: MIT Press.

Squire, L. R. (2004). Memory systems of the brain: A brief history and current perspective. Neurobiology of Learning and Memory, 82, 171-177. https://doi.org/10.1016/j.nlm.2004.06.005

Talarico, J. M., LaBar K. S., \& Rubin, D. C. (2004). Emotional intensity predicts autobiographical memory experience. Memory \& Cognition, 32, 1118-1132. https://doi.org/10.3758/BF03196886

Thompson, C. P., Skowronski, J. J., Larsen, S. F., \& Betz, A. L. (1996). Autobiographical memory: Remembering what and remembering when. Erlbaum: Mahwah. 
Tulving, E. (1972). Episodic and semantic memory. In E. Tulving \& W. Donaldson (Eds.), Organization of memory (pp. 381-402). New York, NY: Academic Press.

Tulving, E. (1983). Elements of episodic memory. Oxford: Clarendon.

Tulving, E. (1984). Précis of elements of episodic memory. Behavioral and Brain Sciences, 7, 223-268. https://doi.org/10.1017/ S0140525X0004440X

Tulving, E. (1985). Memory and consciousness. Canadian Psychology, $26,1-12$.

Tulving, E. (1993). What Is episodic memory? Current Directions in Psychological Science, 2(3), 67-70. https://doi.org/10.1111/14678721.ep10770899

Tulving, E. (2002). Episodic memory: From mind to brain. Annual Review of Psychology, 53, 1-25. https://doi.org/10.1146/annurev. psych.53.100901.135114

Tulving, E. (2005). Episodic memory and autonoesis: Uniquely human? In H. S. Terrace \& J. Metcalfe (Eds.) The missing link in cognition: Origins of self- reflective consciousness (pp. 3-56). New York: Oxford University Press.
Tulving, E., Schacter, D. L., McLachlan, D. R., Moscovitch, M. (1988). Priming of semantic autobiographical knowledge: A case study of retrograde amnesia. Brain and Cognition, 8(1), 3-20. https://doi. org/10.1016/0278-2626(88)90035-8

Warrington, E. K., \& McCarthy, R. A. (1988). The fractionation of retrograde amnesia. Brain and Cognition, 7, 184-200. https://doi.org/ 10.1016/0278-2626(88)90029-2

Weidemann, G., Best, E., Lee, J. C., \& Lovibond, P. F. (2013). The role of contingency awareness in single-cue human eyeblink conditioning. Learning \& Memory, 20, 363-366. https://doi.org/10.1101/lm. 029975.112

Wilson, B. A., \& Wearing, D. (1995). Prisoner of consciousness: A state of just awakening following herpes simplex encephalitis. In R. Campbell \& M. A. Conway (Eds). Broken memories: Case studies in memory impairment (pp. 14-30). Malden: Blackwell.

Publisher's note Springer Nature remains neutral with regard to jurisdictional claims in published maps and institutional affiliations. 